\title{
One-step Nucleic Acid Amplification (OSNA) Fits Better with Lower Cost in Breast Cancer Axillary Management
}

\author{
Fabio Corsi ${ }^{1 *}$, Luca Sorrentino ${ }^{1}$, Alessandra Sartani ${ }^{1}$, Daniela Bossi ${ }^{1}$, Marta \\ Truffi ${ }^{2}$, Diego Foschi ${ }^{1}$ \\ ${ }^{1}$ Department of Biomedical and Clinical Sciences, Surgery Division, University of Milan, “Luigi Sacco" Hospital, via G. B. Grassi 74, 20157 Milano, Italy \\ ${ }^{2}$ Department of Biomedical and Clinical Sciences University of Milan, "Luigi Sacco" Hospital, via G. B. Grassi 74, 20157 Milano, Italy
}

Received: 08 April, 2016; Accepted: 19 April, 2016; Published: 29 April, 2016

*Corresponding author: Fabio Corsi, MD, Professor, Breast Unit, Department of Clinical Sciences University of Milan, "Luigi Sacco" University Hospital, Via G. B. Grassi 74, 20157 Milano, Italy, Tel.: +39.02.3904.3449; Fax: +39.02.5031.9846; E-mail: fabio.corsi@unimi.it

\begin{abstract}
Introduction: One-Step Nucleic Acid Amplification (OSNA) has been already validated for analysis of sentinel lymph node (SLN) in breast cancer. We investigated benefits of OSNA beyond accuracy, with a focus on cost-effectiveness.

Methods: 253 consecutive breast cancer patients were reviewed: SLN was analyzed by OSNA in 114 cases and by standard histopathology in 139 cases. Nodal involvement detection, reintervention rate, time between surgery and adjuvant therapy were assessed. A cost analysis of OSNA vs. standard histopathology was performed.

Results: With OSNA the re-intervention rate significantly decreased $(10.79 \%$ vs. $0 \%, \mathrm{p}=0.0003)$, and adjuvant therapy started earlier (38.5 days vs. 23.8 days, $p<0.0001$ ). Total cost per patient was $5,990.8 €$ for histopathology vs. $4,308 €$ with OSNA $(\mathrm{p}<0.0001)$ if positive SLN. In case of negative SLN costs were similar $(2,419.6 €$ vs. $2,425.2 €, \mathrm{p}=0.947)$.
\end{abstract}

Conclusions: OSNA reduces re-interventions, allows to start earlier adjuvant therapy and is more cost-effective than histopathology.

Keywords: Breast cancer; Sentinel lymph node biopsy; OSNA; Cost analysis

\section{Introduction}

Intraoperative assessment of nodal status should be recommended in breast conservative surgery, since it avoids a second operation for axillary dissection in case of positive sentinel lymph node (SLN), with a subsequent decreased psychological burden for patients, a reduction in re-hospitalization and related costs, and the avoidance of delay between surgery and the onset of adjuvant therapy [1-3]. The most frequent technique for assessing the presence of nodal involvement is the histopathological analysis with Hematoxylin and Eosin (HE) stain plus immunohistochemistry (IHC), but its intraoperative use requires a long time and a heavy involvement of Pathology Departments to obtain an accurate nodal status assessment, thus it is available in a few Breast Units only $[1,2,4]$. Therefore, a large part of Institutes are forced to analyze the SLN postoperatively, with evident disadvantages for patients and increased costs due to the eventuality of a second hospitalization for axillary surgery [5]. Frozen section and imprint cytology have been proposed as appealing alternative techniques to obtain an intraoperative examination of SLN, but their sensitivities vary widely among studies, ranging from $17 \%$ to $94 \%[3,6,7]$. Hence these costsaving methods do not guarantee the avoidance of a second surgery for patients. One-Step Nucleic Acid Amplification (OSNA) assay is a rapid and standardized molecular technique, which has been largely validated in literature for intraoperative SLN analysis in comparison with standard histology, thus providing an accurate tool for immediate decisions in management of the axilla $[8,9]$. Aim of our study was to investigate advantages of OSNA beyond its high accuracy for the definitive assessment of nodal involvement, including the possibility of a one-step surgery for both lumpectomy and possible axillary dissection, and subsequent anticipation in the onset of systemic adjuvant therapy. The secondary aim was to provide a comprehensive cost analysis for OSNA, since cost-effectiveness of OSNA still remains largely unknown.

\section{Methods}

\section{Study population and case selection}

From January 2011 to December 2012, we have reviewed data of 253 consecutive breast cancer patients with clinically and sonographically negative axillary nodes, who underwent conservative breast surgery with SLN biopsy at the Breast Unit of "Luigi Sacco" University Hospital in Milan, Italy. In all cases the SLN was identified using $1.5 \mathrm{mCi} / \mathrm{ml}$ of colloidal human serum albumin labelled with $99 \mathrm{mTc}$ injected into the periareolar subdermal area with subsequent lymphoscintigraphy on the day before surgery, and with a gamma-probe (Bluetooth Neoprobe Gamma Detection System) during surgery. The lymphoscintigraphy was performed in another Institute ("Niguarda Ca' Granda" Hospital, Milan, Italy) due to the lack of a Nuclear Medicine Department in our Breast Unit. The SLN biopsy was performed postoperatively in 139 patients with standard HE plus IHC, by embedding the sliced 
lymph node in paraffin wax, taking two adjacent sections every 50 micron and staining one of them with HE and the other one with IHC for cytokeratin [1, 4]. For 114 patients SLN analysis was performed intraoperatively with OSNA system (Sysmex, Kobe, Japan) obtaining a definitive result about nodal status [8, 11]. Nodal involvement has been defined as reported in Table 1 $[10,11]$. For both groups of patients, axillary dissection has been performed in case of macrometastases only [12-14].

\section{Study design and cost analysis}

For each patient we recorded the age at diagnosis, the histological tumor type and grade, the expression of progesterone/estrogen receptors, Ki67, Her2/neu status, and $\mathrm{T}$ staging on final pathology. These variables were compared between the two groups of patients to assess possible population heterogeneity. Then, nodal involvement, rates of second surgery and time between surgery and adjuvant therapy have been compared between histopathology- and OSNA-analyzed patients. Mean operative time and hospitalization duration have been recorded for each group of patients, and for both positive and negative SLN. In case of positive SLN diagnosed by standard histopathology, these variables have been further separated for first surgery and second surgery for axillary dissection.

A cost analysis has been performed comparing OSNA and postoperative histopathological examination of SLN. For cost analysis the mean operative time (minutes) for the two groups of patients have been multiplied by the cost of 1 minute of surgery, according to the Cost Management Office of our Institute i.e. $6.8 €$ per minute, including staff, devices, drugs and sterilization costs. Lymphoscintigraphy costs, including the specific cost of the procedure, the cost of a dose of $99 \mathrm{mTC}$, the cost of lymphoscintigraphy radiological reporting, and the cost of patients transport to the Department of Nuclear Medicine, have also been counted in the analysis. The total cost of lymphoscintigraphy was based on Lombardy Region rates registry for this procedure: $158 €$ per single procedure plus $40 €$ per patient for transport. Hospitalization costs have been calculated by multiplying the hospitalization days by the cost of 1 day of patient stay in the Surgery Department, according to the Cost Management Office of our Institute, i.e. 634€ per patient per day including costs of medical and non medical

Table 1: Definition of isolated tumor cells, micro- and macro metastases according to HE examination or OSNA technique.

\begin{tabular}{|l|c|c|}
\hline & $\begin{array}{c}\text { Histopathology (HE } \\
\text { plus IHC) }\end{array}$ & OSNA examination \\
\hline Negative or ITC & $\begin{array}{c}\text { Tumor cell deposits } \\
<0.2 \mathrm{~mm}\end{array}$ & $<250 \mathrm{mRNA}$ copies/uL \\
\hline Micrometastasis & $\begin{array}{c}\text { Tumor cell deposits } \\
\geq 0.2 \mathrm{~mm} \text { and }<2 \mathrm{~mm}\end{array}$ & $\begin{array}{c}250-5,000 \mathrm{mRNA} \\
\text { copies } / \mathrm{uL}\end{array}$ \\
\hline Macrometastasis & $\begin{array}{c}\text { Tumor cell deposits } \\
\geq 2 \mathrm{~mm}\end{array}$ & $>5,000 \mathrm{mRNA}$ copies/ \\
$\mathrm{uL}$
\end{tabular}

staff, drugs, medical device, clinical tests and accommodation. The analysis has been completed with the cost of examination of SLN by OSNA (372€ per lymph node) or by standard HE plus IHC (335€ per lymph node), including consumables, reagents, staff and depreciated costs. These data have been furnished by the Pathology Department of our Institute. In case of need for a second surgery for axillary dissection, the costs of the two surgical interventions and of the two hospitalizations have been summed. All costs have been expressed in euros (€).

All these costs have been summed to obtain the total cost per patient, which was calculated for the four possible scenarios: positive SLN diagnosed on HE plus IHC, positive SLN analyzed with OSNA, negative SLN diagnosed on HE plus IHC, and negative SLN analyzed with OSNA. Total costs have been compared between the two techniques in case of positive and negative SLN.

\section{Statistical analysis}

Student's T test was used for continuous variables and Fisher exact test for categorical variables. The cost analysis has been performed by Student's T test. A p value $<0.05$ was considered statistically significant. All analyses were carried out using the Stata software version 11.0 (Stata Corp, Austin, TX, USA).

\section{Results}

\section{Nodal involvement detection}

The HE and OSNA groups of patients were comparable for mean age of diagnosis, tumor size, grade, histological type, hormone receptors, Ki67 and Her2 status (Table 2). In 139 cases of histopathology group, 15 macrometastasis (10.79\%) were detected. In 114 cases of OSNA group, 20 macrometastasis (17.54\%) were detected (Table 2). This difference was not statistically significant $(p=0.105)$. In all patients with a macro metastasis, axillary dissection was performed.

\section{Re-intervention rates for axillary surgery and timing of adjuvant therapy}

In HE group all the axillary dissections were necessarily performed with a second surgery, while with OSNA method a one-step surgery was possible in all cases. Therefore, the reintervention rate for axillary dissection was $10.79 \%$ (15/139) for HE and $0 \%(0 / 114)$ for OSNA, $p=0.0003$. Consequently, mean time between initial surgery and the onset of adjuvant therapy resulted to be significantly higher in patients with metastatic SLN analysed by histopathology (38.5 days, \pm 16.1 ) compared to those analysed by OSNA (23.8 days, \pm 7.7 ), $\mathrm{p}<0.0001$, with a significant decrease in the delay before systemic therapy with OSNA (Table 3).

\section{Surgery times and hospitalization stay}

Mean surgery times in case of negative SLN were slightly higher with OSNA: $67.7 \mathrm{~min}( \pm 17.8)$ versus $63 \mathrm{~min}( \pm 19,2)$ for HE $(\mathrm{p}=0.066)$. For positive SLN, summed times of first and second surgery were comparable in the two groups: $122 \mathrm{~min}( \pm 27.6)$ in HE group vs. $111.5 \min ( \pm 31.8)$ in OSNA group ( $p=0.314)$. Mean hospitalization time was similar in case of negative SLN (2.3 days 


\begin{tabular}{|c|c|c|c|c|}
\hline Characteristic & $\begin{array}{l}\text { Histopathology } \\
\text { n, (\%) }\end{array}$ & $(n=139)$ & $\begin{array}{l}\text { OSNA } \\
\mathrm{n},(\%)\end{array}$ & p value \\
\hline \multicolumn{5}{|l|}{ Tumor size } \\
\hline pTis & $33(23.74 \%)$ & & $24(21.05 \%)$ & \multirow{4}{*}{0.825} \\
\hline pT1 & $88(63.31 \%)$ & & $77(67.54 \%)$ & \\
\hline pT2 & $15(10.79 \%)$ & & $12(10.53 \%)$ & \\
\hline pTx & $3(2.16 \%)$ & & $1(0.88 \%)$ & \\
\hline \multicolumn{5}{|l|}{ Histological grade } \\
\hline G1 & $39(28.06 \%)$ & & $37(32.46 \%)$ & \multirow{3}{*}{0.646} \\
\hline G2 & $65(46.76 \%)$ & & $47(41.23 \%)$ & \\
\hline G3 & $35(25.18 \%)$ & & $30(26.31 \%)$ & \\
\hline \multicolumn{5}{|l|}{ Tumor type } \\
\hline Invasive ductal & $96(69.06 \%)$ & & $84(73.68 \%)$ & \multirow{3}{*}{0.759} \\
\hline Invasive lobular & $7(5.04 \%)$ & & $5(4.39 \%)$ & \\
\hline DCIS & $36(25.90 \%)$ & & $36(25.90 \%)$ & \\
\hline \multicolumn{5}{|l|}{ Estrogen receptors } \\
\hline Negative & $17(12.23 \%)$ & & $18(15.79 \%)$ & \multirow[b]{2}{*}{0.466} \\
\hline Positive & $122(87.77 \%)$ & & $122(87.77 \%)$ & \\
\hline \multicolumn{5}{|l|}{ Progesterone receptors } \\
\hline Negative & $42(30.22 \%)$ & & $35(30.70 \%)$ & \multirow[b]{2}{*}{1.000} \\
\hline Positive & $97(69.78 \%)$ & & $79(69.30 \%)$ & \\
\hline \multicolumn{5}{|l|}{ Ki67 } \\
\hline$\leq 14 \%$ & $68(48.92 \%)$ & & $61(53.51 \%)$ & \multirow[b]{2}{*}{0.528} \\
\hline$>14 \%$ & $71(51.08 \%)$ & & $53(46.49 \%)$ & \\
\hline \multicolumn{5}{|l|}{ Her2/neu status } \\
\hline Positive & $13(9.35 \%)$ & & $15(13.16 \%)$ & \multirow{2}{*}{0.421} \\
\hline Negative & $126(90.65 \%)$ & & $99(86.84 \%)$ & \\
\hline \multicolumn{5}{|l|}{ Sentinel node status } \\
\hline Micrometastasis & $3(2.16 \%)$ & & $6(5.27 \%)$ & \multirow{3}{*}{0.105} \\
\hline Macrometastasis & $15(10.79 \%)$ & & $20(17.54 \%)$ & \\
\hline Negative/ITC & $121(87.05 \%)$ & & $88(77.19 \%)$ & \\
\hline $\begin{array}{l}\text { Mean age of diagnosis, year } \\
\text { (range) }\end{array}$ & $62(38-82)$ & & $62.5(29-83)$ & 1.000 \\
\hline
\end{tabular}

Table 3: Rates of second surgery for axillary dissection and time between surgery and adjuvant therapy between histopathology and OSNA group of patients.

\begin{tabular}{|l|c|c|c|}
\hline $\begin{array}{l}\text { Second surgery for axillary dissection } \\
\text { n, (\%) }\end{array}$ & Histopathology & OSNA & p value \\
\hline $\begin{array}{l}\text { Time between surgery and adjuvant } \\
\text { therapy (days) }\end{array}$ & $15(10.79 \%)$ & $0(0 \%)$ & 0.0003 \\
\hline
\end{tabular}

\pm 1.1 for HE vs. 2.2 days \pm 0.7 for OSNA, $p=0.442$ ), while it was significantly higher in histology group of patients for positive SLN (7.3 days \pm 1.4 vs. 4.7 days $\pm 1.6, \mathrm{p}<0.0001)$.

\section{Cost analysis}

Surgery costs based on operative times and including the specific costs of SLN examination (335€ per node for HE plus IHC, $372 €$ per node for OSNA) were $763.4 €( \pm 130.6 €)$ for histology and $832.4 €( \pm 121 €)$ for OSNA $(\mathrm{p}<0.0001)$ in case of negative SLN. In case of positive SLN, the summed cost of surgery for HE group was $829.6 €( \pm 188 €)$, while cost for OSNA was $758.2 €$ $( \pm 216.2 €), p=0.315$.
Hospitalization costs in case of negative SLN resulted to be $1,458.2 €( \pm 697.4 €)$ for $\mathrm{HE}$ and $1,394.8 €( \pm 443.8 €)$ for OSNA, $p=0.442$; in case of positive SLN, these costs were $4,628.2 €$ $( \pm 896.6 €)$ for HE and $2,979.8 €( \pm 1,014.4 €)$ for OSNA, $p<0.0001$.

Total cost per patient, including surgery, hospitalization and fixed costs for lymphoscintigraphy and patient transport have been determined for each group and subsequently for each SLN status. In case of positive SLN total cost per patient was $5,990.8 €$ $( \pm 916.1 €)$ for HE plus IHC vs. $4,308 €( \pm 1,037.2 €)$ with OSNA $(\mathrm{p}<$ $0.0001)$; in case of negative SLN it was $2,419.6 €( \pm 709.5 €)$ for HE plus IHC vs. $2,425.2 €( \pm 460 €)$ with OSNA, $p=0.947$. All these data are reported in Table 4 . 


\begin{tabular}{|c|c|c|c|c|c|c|c|c|}
\hline & \multicolumn{4}{|c|}{ Histopathology $(n=139)$} & \multicolumn{4}{|c|}{ OSNA $(n=114)$} \\
\hline & $\begin{array}{l}\text { LNS+ } \\
(n=15)\end{array}$ & Costs & $\begin{array}{c}\text { LNS- } \\
(\mathrm{n}=124)\end{array}$ & Costs & $\begin{array}{l}\text { LNS+ } \\
(\mathrm{n}=20)\end{array}$ & Costs & $\begin{array}{l}\text { LNS- } \\
(\mathrm{n}=94)\end{array}$ & Costs \\
\hline $\begin{array}{l}\text { Mean operative time } \\
\text { (first surgery) }-6.8 € \\
\text { per min }\end{array}$ & $53.2( \pm 19.5)$ & $\begin{array}{c}361.8 € \\
( \pm 132.6 €)\end{array}$ & $63( \pm 19.2)$ & $\begin{array}{c}428.4 € \\
( \pm 130.6 €)\end{array}$ & $\begin{array}{c}111.5 \\
( \pm 31.8)\end{array}$ & $758.2 €( \pm 216.2 €)$ & $67.7( \pm 17.8)$ & $\begin{array}{l}460.4 € \\
( \pm 121 €)\end{array}$ \\
\hline $\begin{array}{l}\text { Mean hospitalization } \\
\text { stay (first surgery) - } \\
634 € \text { per day }\end{array}$ & $2.4( \pm 1)$ & $\begin{array}{l}1,521.6 € \\
( \pm 634 €)\end{array}$ & $2.3( \pm 1.1)$ & $\begin{array}{l}1,458.2 € \\
( \pm 697.4 €)\end{array}$ & $4.7( \pm 1.6)$ & $\begin{array}{c}2,979.8 € \\
( \pm 1,014.4 €)\end{array}$ & $2.2( \pm 0.7)$ & $\begin{array}{l}1,394.8 € \\
( \pm 443.8 €)\end{array}$ \\
\hline $\begin{array}{l}\text { Mean operative time } \\
\text { (second surgery) - } \\
6.8 € \text { per min }\end{array}$ & $68.8( \pm 19.6)$ & $\begin{array}{c}467.8 € \\
( \pm 133.3 €)\end{array}$ & - & - & - & - & - & - \\
\hline $\begin{array}{l}\text { Mean hospitalization } \\
\text { stay (second surgery) } \\
\text { - } 634 € \text { per day }\end{array}$ & $4.9( \pm 1)$ & $\begin{array}{l}3,106.6 € \\
( \pm 634 €)\end{array}$ & - & - & - & - & - & - \\
\hline $\begin{array}{l}\text { Total cost per } \\
\text { patient* }\end{array}$ & \multicolumn{2}{|c|}{$5,990.8 €( \pm 916.1 €)^{* *}$} & \multicolumn{2}{|c|}{$2,419.6 €( \pm 709.5 €)$} & \multicolumn{2}{|c|}{$4,308 €( \pm 1037.2 €)^{* *}$} & \multicolumn{2}{|c|}{$2,425.2 €( \pm 460 €)$} \\
\hline
\end{tabular}

*Including lymphoscintigraphy and patient transport (158€+40€) and SLN analysis (HE plus IHC 335€, OSNA 372€).

$* * p<0.0001$

\section{Discussion}

Histopathological examination of SLN with HE staining and IHC is the most commonly used technique; however intraoperative step-sectioning every 50 micron of SLN is a strain on Pathology Departments resources and requires both a specific team of pathologists, which is often unavailable, and long procedure times (mean time of 50 minutes) [1, 3]. Therefore in several Institutes intraoperative histopathological analysis of SLN is unfeasible, and a second surgery for axillary dissection in case of positive SLN is generally necessary, with disadvantages in terms of impact on the quality of patients life and second hospitalizations $[15,16]$. To overcome these limitations, some alternative techniques have been proposed to assess the status of SLN, such as imprint cytology and frozen sections analysis. However, their sensitivities vary widely due to the lack of standardization and to lower accuracy [3, 17-22]. Particularly about imprint cytology, one of the largest meta-analyses on 31 studies showed a pooled overall sensitivity equal to $63 \%$ when used intraoperatively [7]. This sensitivity should be considered unacceptably low for a proper intraoperative evaluation of the axilla.

In our series OSNA has demonstrated to be an accurate and standard technique for sentinel node assessment, as previously reported in several validation studies [8, 23-26]. Moreover, the use of OSNA has reduced our second surgery rate for axillary dissection from $10.79 \%$ to $0 \%(p=0.0003)$ thanks to its high intraoperative accuracy, thus demonstrating a role of OSNA in reducing second hospitalizations, with subsequent reduced patients discomfort. Klingler, et al. [16] have shown a similar reduction in the re-intervention rate for axillary dissection by using OSNA intraoperatively ( $9 \%$ vs. 39\% if OSNA was not performed, $\mathrm{p}<0.01$ ). Furthermore, this rapid decision-making on the axilla allows a prompt starting of adjuvant therapy, with significant reduction in time between surgery and adjuvant treatment in patients with an involved SLN (23.8 days in case of intraoperative OSNA vs. 38.5 days with postoperative histopathology, $\mathrm{p}<0.0001$ ).

A less investigated feature of OSNA is cost-effectiveness, which is a matter of debate since OSNA is more expensive than morphological examination of the SLN [27]. A comprehensive cost-analysis of OSNA should include three levels of assessment: surgery costs, hospitalization costs, and pathological examination costs [27]. Surgery costs mainly vary as a function of the operative times, and in our series mean time of surgery was rather higher when including OSNA intraoperative assay (67.7 vs. 63 minutes without intraoperative assessment in case of negative SLN, p $=0.066$ ). However, as expected, the two mean times were not significantly different, because in our centre the SLN biopsy is performed before the lumpectomy, and thus the waiting time of OSNA is spent in excision of the tumor without further elongation of surgery. For positive SLN patients mean operative times between the two groups were not different (122 vs. 111.5 min in HE and OSNA groups, respectively, $p=0.314$ ), because the longer time required by OSNA is balanced by the longer time required for a new surgical access to the axilla in case of a second surgery. Considering only operative times and specific examination costs, OSNA is therefore more expensive in case of negative SLN (832.4€ vs. 763.4€, p $<0.0001$ ), but on the other hand it is comparable to histopathology in case of positive SLN (758.2€ vs. 829.6€, $\mathrm{p}=0.315$ ). As expected, mean hospitalization time was similar in the two groups in case of negative SLN (2.3 vs. 2.2 days), but increased significantly in histopathology group in case of positive SLN due to the need of readmission (7.3 vs. 4.7 days, $\mathrm{p}<0.0001)$. As a consequence, hospitalization costs in case of negative SLN resulted to be similar between the two groups $(1,458.2 €$ vs. $1,394.8 €)$, but in case of the need of axillary dissection these costs markedly rise for HE group $(4,628.2 €$ vs. 2,979.8€, $\mathrm{p}<0.0001$ ).

Considering surgery, hospitalization, pathology examination and fixed costs together, it was evident that OSNA is globally 
cost-effective compared to post-operative histopathology, since total costs were identical between the two groups of patients in case of negative SLN $(2,419.6 €$ vs. $2,425.2 €, p=0.947)$, and strongly favourable for OSNA in case of positive SLN $(4,308 €$ vs. $5,990.8 €, p<0.0001)$. These data suggest that, in case of a second hospitalization for further axillary surgery, global costs are not sustainable, and from this point of view OSNA becomes even more appealing.

Similar results have been reported in a recent cost-benefit French study in which the SLN has been analyzed by OSNA or by conventional post-operative histopathology [27]. The average pathology examination cost was markedly higher for OSNA (291.84€ vs. 35.04€); however, since the hospital stay was much longer in histopathology group due to re-hospitalization for axillary surgery (5.4 vs. 4.2 days), total cost of OSNA was lower compared to histopathology [27]. Notably, the reported costs for histopathology examination (35.04€) were much lower than that obtained in our study, but the Authors have not included staff costs. Interestingly, a significant cost difference between the two techniques was evident considering separately patients with or without axillary dissection, which was a common finding also in our study. Another relevant cost-benefit analysis by the Spanish group of Guillén-Paredes [28] has pointed out a reduction in total hospital stay with OSNA, saving up to $199.69 €$ per patient for hospitalization costs. Finally, a more complex analysis has been provided in a British study based on three different cost-analysis pathways: lumpectomy with axillary dissection, lumpectomy with SLN biopsy and postoperative histopathology, and lumpectomy with molecular analysis of the SLN [5]. Although this study demonstrated a substantial cost-effectiveness of molecular analysis compared to standard histopathology, it also highlighted that in some countries the avoidance of a second surgery with subsequent loss of reimbursement from National Health Services could discourage the adoption of intraoperative SLN examinations [5].

\section{Conclusion}

OSNA is a standard and reproducible technique for highly accurate intraoperative examination of the SLN, comparable to postoperative histopathology with immunohistochemistry. Intraoperative use of OSNA significantly reduces the rate of second surgery for axillary dissection, with a strongly reduced discomfort for patients and a prompt start of adjuvant therapy. The charm of this technique also relies on its demonstrated costeffectiveness, which allows significant saving of money in case of nodal involvement due to the avoidance of a re-hospitalization.

\section{Acknowledgements}

The Authors declare that there are not acknowledgements or funding sources to disclose.

\section{References}

1. Viale G, Bosari S, Mazzarol G, Galimberti V, Luini A, Veronesi P, et al. Intraoperative examination of axillary sentinel lymph nodes in breast carcinoma patients. Cancer. 1999;85(11):2433-2438.

2. Zurrida S, Mazzarol G, Galimberti V, Renne G, Bassi F, Iafrate F, et al.
The problem of the accuracy of intraoperative examination of axillary sentinel nodes in breast cancer. Ann Surg Oncol. 2001;8(10):817-820.

3. Layfield DM, Agrawal A, Roche H, Cutress RI. Intraoperative assessment of sentinel lymph nodes in breast cancer. Br J Surg. 2011;98(1):4-17. doi: $10.1002 /$ bjs.7229.

4. Viale G, Mastropasqua MG, Maiorano E, Mazzarol G. Pathologic examination of the axillary sentinel lymph nodes in patients with early-stage breast carcinoma: Current and resolving controversies on the basis of the European Institute of Oncology experience. Virchows Arch. 2006;448(3):241-247.

5. Cutress RI, McDowell A, Gabriel FG, Gill J, Jeffrey MJ, Agrawal A, et al. Observational and cost analysis of the implementation of breast cancer node intraoperative molecular diagnosis. J Clin Pathol. 2010;63(6):522-529. doi: 10.1136/jcp.2009.072942.

6. Taffurelli M, Montroni I, Santini D, Fiacchi M, Zanotti S, Ugolini G, et al. Effectiveness of sentinel lymph node intraoperative examination in 753 women with breast cancer: Are we overtreating patients? Ann Surg. 2012;255(5):976-980. doi: 10.1097/ SLA.0b013e31824def4e.

7. Tew K, Irwig L, Matthews A, Crowe P, Macaskill P. Meta-analysis of sentinel node imprint cytology in breast cancer. Br J Surg. 2005;92(9):1068-1080.

8. Tamaki Y, Sato N, Homma K, Takabatake D, Nishimura R, Tsujimoto $\mathrm{M}$, et al. Routine clinical use of the one-step nucleic acid amplification assay for detection of sentinel lymph node metastases in breast cancer patients: results of a multicenter study in Japan. Cancer. 2012;118(14):3477-3483. doi: 10.1002/cncr.26683.

9. Castellano I, Macrì L, Deambrogio C, Balmativola D, Bussone R, Ala A, et al. Reliability of whole sentinel lymph node analysis by One-Step Nucleic Acid Amplification for intraoperative diagnosis of breast cancer metastases. Ann Surg. 2012;255(2):334-342. doi: 10.1097/ SLA.0b013e31823000ed.

10. Edge SB, Byrd DR, Compton CC, Fritz AG, Greene FL, Trotti A. American Joint Committee on Cancer Staging Manual $7^{\text {th }}$ ed. New York: SpringerVerlag, 2010.

11. Tsujimoto M, Nakabayashi K, Yoshidome K, Kaneko T, Iwase T, Akiyama F, et al. One-step nucleic acid amplification for intraoperative detection of lymph node metastasis in breast cancer patients. Clin Cancer Res. 2007;13(16):4807-4816.

12. Li D, Xu X, Chen J, Chen J, Yang B, Yang W, et al. Utility of one-step nucleic acid amplification (OSNA) assay in detecting breast cancer metastases of sentinel lymph nodes in a Chinese population. Breast Cancer. 2015;22(2):135-140. doi: 10.1007/ s12282-013-0461-7.

13. Sagara Y, Ohi Y, Matsukata A, Yotsumoto D, Baba S, Tamada S, et al. Clinical application of the one-step nucleic acid amplification method to detect sentinel lymph node metastasis in breast cancer. Breast Cancer. 2013;20(2):181-186. doi: 10.1007/s12282-011-0324-z.

14. Tamaki Y. One-step nucleic acid amplification assay (OSNA) for sentinel lymph node biopsy. Breast Cancer. 2015;22(3):230-4. doi: 10.1007/s12282-012-0390-x.

15. Classe JM, Baffert S, Sigal-Zafrani B, Fall M, Rousseau C, Alran S, et al. Cost comparison of axillary sentinel lymph node detection and axillary lymphadenectomy in early breast cancer. A national study based on a prospective multi-institutional series of 985 patients 'on behalf of the Group of Surgeon from the French Unicancer Federation'. Ann Oncol. 2012;23(5):1170-1177. doi: 10.1093/annonc/mdr355.

16. Klingler S, Marchal F, Rauch P, Kenouchi O, Chrétien AS, Genin P, et al. Using one-step nucleic acid amplification (OSNA) for intraoperative 
detection of lymph node metastasis in breast cancer patients avoids second surgery and accelerates initiation of adjuvant therapy. Ann Oncol. 2013;24(9):2305-2309. doi: 10.1093/annonc/mdt160.

17. Brogi E, Torres-Matundan E, Tan LK, Cody HS $3^{\text {rd }}$. The results of frozen section, touch preparation, and cytological smear are comparable for intraoperative examination of sentinel lymph nodes: a study in 133 breast cancer patients. Ann Surg Oncol. 2005;12(2):173-180.

18. Liu LC, Lang JE, Lu Y, Roe D, Hwang SE, Ewing CA, et al. Intraoperative frozen section analysis of sentinel lymph node in breast cancer. Cancer. 2011;117(2):250-258. doi: 10.1002/cncr.25606.

19. Aihara T, Munakata S, Morino H, Takatsuka Y. Comparison of frozen section and touch imprint cytology for evaluation of sentinel lymph node metastasis in breast cancer. Ann Surg Oncol. 2004;11(8):747750.

20. Litz CE, Beitsch PD, Roberts CA, Ewing G, Clifford E. Intraoperative cytologic diagnosis of breast sentinel lymph nodes in the routine, nonacademic setting: a highly specific test with limited sensitivity. Breast J. 2004;10(5):383-387. doi: 10.1111/j.1075122X.2004.21360.x.

21. Guidroz JA, Johnson MT, Scott-Conner CE, De Young BR, Weigel RJ. The use of touch preparation for the evaluation of sentinel lymph nodes in breast cancer. Am J Surg. 2010;199(6):792-796. doi: 10.1016/j. amjsurg.2009.06.020.

22. Jensen AJ, Naik AM, Pommier RF, Vetto JT, Troxell ML. Factors influencing accuracy of axillary sentinel lymph node frozen section for breast cancer. Am J Surg. 2010;199(5):629-635. doi: 10.1016/j. amjsurg.2010.01.017.
23. Cserni G. Intraoperative analysis of sentinel lymph nodes in breast cancer by one-step nucleic acid amplification. J Clin Pathol. 2012;65(3):193-199. doi: 10.1136/jclinpath-2011-200301.

24. Schem C, Maass N, Bauerschlag DO, Carstensen MH, Löning T, Roder C, et al. One-step nucleic acid amplification: a molecular method for the detection of lymph node metastases in breast cancer patients; results of the German study group. Virchows Arch. 2009;454(2):203-210. doi: 10.1007/s00428-008-0703-9.

25. Feldman S, Krishnamurthy S, Gillanders W, Gittleman M, Beitsch PD, Young PR, et al. A novel automated assay for the rapid identification of metastatic breast carcinoma in sentinel lymph nodes. Cancer. 2011;117(12):2599-2607. doi: 10.1002/cncr.25822.

26. Shimazu K, Noguchi S. Clinical significance of breast cancer micro metastasis in the sentinel lymph node. Surg Today. 2016;46(2):155160. doi: 10.1007/s00595-015-1168-5.

27. Raia-Barjat T, Trombert B, Khaddage A, Douchet C, Seffert P, Peoc'h M, et al. OSNA (one-step nucleic acid amplification) sentinel lymph node intraoperative molecular analysis in breast cancer: a cost-benefit analysis. Med Oncol. 2014;31(12):322. doi: 10.1007/s12032-0140322-z.

28. Guillén-Paredes MP, Carrasco-Gonzàlez L, Chàves-Benito A, AguayoAlbasini JL. One step nucleic acid amplification (OSNA) assay for sentinel lymph node metastases as an alternative to conventional postoperative histology in breast cancer: A cost-benefit analysis. Cir Esp. 2011;89(7):456-462. doi: 10.1016/j.ciresp.2011.04.013. 